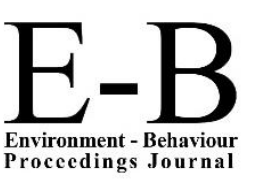

\title{
AicE-Bs2015Barcelona
}

$6^{\text {th }}$ Asia-Pacific International Conference on Environment-Behaviour Studies, Barcelona School of Architecture (ETSAB), Barcelona, Spain, 31 Aug.- 05 Sep. 2015

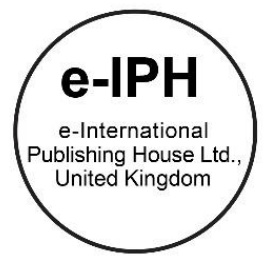

\section{Environmental Mapping Framework and Childhood Obesity in Selangor, Malaysia}

\author{
Hayati Adilin Mohd Abd Majid 1*, Ajau Danis ${ }^{2}$, Siti Khuzaimah Ahmad Sharoni ${ }^{3}$, Mastura Khalid ${ }^{4}$ \\ ${ }^{1}$ Food Service Department, Faculty of Hotel \& Tourism Management,UiTM, Dungun Campus, 24300 Terengganu, Malaysia \\ ${ }^{2}$ Basic Science Department, Faculty of Health Sciences, UiTM, Puncak Alam Campus, 42300 Puncak Alam, Selangor, Malaysia \\ ${ }^{3}$ Nursing Department, Faculty of Health Sciences, UiTM, Puncak Alam Campus, 42300 Puncak Alam, Selangor, Malaysia \\ ${ }^{4}$ Nutrition\& Dietetic Department, Faculty of Health Sciences, UiTM, Puncak Alam Campus, 42300 Puncak Alam, Selangor, Malaysia
}

\begin{abstract}
The schools environment might be one of the factors that contribute to childhood obesity since children spent most of their time at school. This study aimed to identify the compliance of selected schools in Selangor, Malaysia with whole-school mapping framework and prevalence of obesity among primary school children in rural and urban environmental settings. A total of 1200 children aged 10-11 years from 60 schools in rural and urban area in Selangor involved in this study and their BMI was calculated. The compliance of each school environmental factors was determined by using whole-school environmental mapping framework's questionnaires.

(C) 2016. The Authors. Published for AMER ABRA by e-International Publishing House, Ltd., UK. Peer-review under responsibility of AMER (Association of Malaysian Environment-Behaviour Researchers), ABRA (Association of Behavioural Researchers on Asians) and cE-Bs (Centre for Environment-Behaviour Studies, Faculty of Architecture, Planning \& Surveying, Universiti Teknologi MARA, Malaysia.
\end{abstract}

Keywords: Childhood obesity; whole-school environmental mapping; BMI status; rural and urban settings

\section{Introduction}

The prevalence of obesity and overweight has increased worldwide more dramatically with a significant variation in trends across countries. Many risk factors that can contribute to obesity such as genetic, diet intake, physical activity and the sedentary lifestyle. However nowadays, childhood obesity has become a major health concerns worldwide. According to National Centers for Disease Control and Prevention (2011) childhood obesity increased from $6.5 \%$ in 1980 to $19.6 \%$ in 2008 among children aged 6 to 12 years old. It shows that childhood obesity has more than tripled in 30 years. Besides, the prevalence of childhood obesity has reached epidemic levels in developing countries, and about $16.9 \%$ of children and adolescents in the US are obese (Ogden, Carroll, Kit, \& Flegal, 2012). In China, there are more than 20\% of children aged 7-17 years are obese and overweight (Wang, Kong, Wu, Bai, \& Burton, 2005). Meanwhile in Thailand, the obesity cases among children aged 5 to 12 years old increased about $3.4 \%$ within two years (WHO, 2003). In Malaysia, it has been reported that this country has become the highest

\footnotetext{
* Corresponding author. Tel.: +0-000-000-0000

E-mail address: hayati2959@tganu.uitm.edu.my
} 
obesity prevalence in the Southeast Asian Region. The prevalence of obesity for both sexes contributes about $44.2 \%$ of the Malaysian population (WHO, 2011).

Besides, childhood obesity has also begun to rise in developing countries such as Malaysia, in which malnutrition and vitamin-deficiency-related diseases still represent a significant public health concern. Within 30 years, Malaysia has undergone a transition from under- nutrition to the relative over nutrition. According to Khambalia, Lim, Gill, and Bulgiba (2012), the incidence of underweight children has decreased from $55 \%$ to $14.4 \%$ within one decade. Meanwhile, according to them, the number of overweight children has increased from $4 \%$ to $9.8 \%$. Besides, referring to obesity statistics from the Malaysian National Health and Morbidity Survey in 2006 showed that $38 \%$ of the child population in Malaysia that having overweight (Kee et al., 2008). Overweight prevalence among primary school-age children in Peninsular of Malaysia also shown an increment of $5.8 \%$ within six years, in which $20.7 \%$ in 2002 to $26.5 \%$ in 2008 (Ismail et al., 2008).

The epidemic of obesity and overweight among Malaysian children in the age range of 7 to 12 increased about $7.8 \%$ in Selangor (Bong \& Safurah, 1996). Also, Ismail (2002) revealed a more dramatic prevalence of obesity among children aged 6-12 years. Among 11,500 students involved in the survey, 20.7\% of them are overweight and obese. The recent Nutrition Survey of Malaysian Children (SEANUTS Malaysia) in 2011 shown a total of $21.6 \%$ of overweight and obese children. It proved that the childhood obesity rates keep increasing widely in Malaysia. Some of the factors that mostly lead to obesity among children are diet intake, sedentary lifestyles and environmental factor. It is of particular concern due to its associated link with adult obesity and related health consequences, such as diabetes and cardiovascular diseases (Lobstein, Baur, \& Uauy, 2004).

Regarding the increasing number of overweight and obesity among children, school environments become one of the factors that might have an influence on the health-related behavior of the children. Schools represent a critical environment in which children spend much time at school and consume a substantial proportion of their daily intake at school (Hayati, Ajau, Siti \& Mastura, 2015). Moreover, schools not only act as institutions that emphasis on academic accomplishment, but it also accentuates a particular value and prospects of the child through the academic culture's influence.

Whole-school mapping framework can be defined as school environmental factors that consists of 4 types of environment in the school. The school environmental factors are consists of physical, economic, political and socio-cultural aspects (Hayati, Ajau, Siti Khuzaimah \& Mastura, 2015). The school environmental factors such as physical, economic, political and socio-cultural are believed to give a weight toward the occurrence of childhood obesity (Ogden, Carroll, Kit, \& Flegal, 2012). The components of Whole School Environmental Mapping is shown in Table 1

Table 1: "Whole School Environmental Mapping" inspired by Analysis Grid for Environments Linked to Obesity (ANGELO) Framework and 'School Food Pack'

\begin{tabular}{|c|c|}
\hline \multirow[t]{3}{*}{ Physical environmental (What is available?) } & $\begin{array}{l}\text { Curriculum and other physical support (i.e. education, } \\
\text { facilities) }\end{array}$ \\
\hline & Food and drink provision \\
\hline & Food and drinks at school canteen \\
\hline \multirow[t]{3}{*}{ Economic environment (What are the costs?) } & Mobile Caterers \\
\hline & Vending Machine \\
\hline & Tuck Shop \\
\hline \multirow[t]{3}{*}{ Political environment (What are the rules?) } & Nutrition standards and guidelines \\
\hline & School policy and rules \\
\hline & Policy makers \\
\hline \multirow[t]{7}{*}{ Socio-cultural environment (What are the attitudes and belief?) } & Food culture and preferences \\
\hline & Collaborations \\
\hline & Use of food as a reward \\
\hline & Role models \\
\hline & Growing food \\
\hline & Barriers and problems \\
\hline & Suggestions and needs \\
\hline
\end{tabular}


The children have a wide variety of eating choices and opportunities at school. The children's diet is influenced by the foods that are available in schools (Anderson, Butcher, \& Levine, 2003). Besides, children may have access to a wide variety of snack foods and drinks through vending machines, school stalls and fundraisers. The availability of unhealthy foods and childhood obesity is problematic in the school environment. School cafeterias and vending machines often sold high energy density food and low in nutritional value (Johnson, Bruemmer, Lund, Evens, \& Mar 2009).

Children's physical activities also influenced by the physical structure of school and physical activity programmes. The school may be the best place for children to play with friends and the curriculum at school needs to be reviewed for whether it ensures sufficient and appropriate physical activity. Dennison, Russo, Burdick, and Jenkins (2004) claimed that the usage of the classroom, the playground and the cafeteria can be used to promote healthy lifestyles in the schools. School playgrounds and access to facilities are important to encourage physical activity among children (Trost et al., 2003). The conducive and supportive school environment can help to decrease childhood overweight and obesity by increasing children's healthy eating behaviour and physical activity levels. Therefore, this study was done to evaluate the school's compliance with "whole-school mapping framework" and prevalence of overweight and obesity among school children in Selangor, Malaysia.

\section{Materials and Method}

A cross-sectional study was conducted involving the children in rural and urban schools in Selangor, Malaysia. A total of 60 schools from urban and rural Selangor were selected for this study, with 30 schools from each setting. The schools were selected randomly from a list of schools available in Selangor, Malaysia. A set of validated Malay version of "whole school environmental mapping" questionnaire (Hayati Adilin, 2011) based on ANGELO Framework (Analysis Grid for Environments Linked to Obesity) was used to interview a teacher (who is responsible for student affairs and the school curriculum) from each school. The components of questionnaire consist of four types of school environmental factors: Physical (what is available) with 35 questions; Economic (what are the costs) with 8 questions; Political (what are the "rules") with 8 questions; and Socio-cultural (what are the attitudes and beliefs) with 10 questions. Data analysis was done by using Social Package for Social Sciences (SPSS) 20.0. The data were coded into SPSS (yes = 1, no = 0), and descriptive statistic was used to examine the percentage of compliance of the school towards the framework. For each four types of environmental factors, a school that obtains more than $60 \%$ score from the questionnaire was considered comply with the "whole school environmental mapping.

Prior to data collection, an approval letter was received from the Ministry of Education, Selangor Department of Education (JPNS) and ethical approval was obtained from Universiti Teknologi MARA Ethical Committee.

\section{Results}

\subsection{The compliance of rural and urban schools with the whole school environmental mapping}

Table 2. The compliance of rural and urban schools with whole school mapping framework

\begin{tabular}{lllllll}
\hline Settings of school & Rural & \multicolumn{3}{l}{ Urban } & \multicolumn{2}{l}{ Total rural and urban } \\
\hline $\begin{array}{l}\text { Compliance of whole school } \\
\text { environmental mapping }\end{array}$ & Comply & Non comply & Comply & Non comply & Comply & Non comply \\
& $\%(n)$ & $\%(n)$ & $\%(n)$ & $\%(n)$ & $\%(n)$ & $\%(n)$ \\
\hline Physical environment & $70.0(21)$ & $30.0(9)$ & $96.7(29)$ & $3.3(1)$ & $83.3(50)$ & $16.7(10)$ \\
Economic environment & $0.0(0)$ & $100.0(30)$ & $20.0(6)$ & $80.0(24)$ & $10.0(6)$ & $90.0(54)$ \\
Political environment & $66.7(20)$ & $33.3(10)$ & $46.7(14)$ & $53.3(16)$ & $56.7(34)$ & $43.3(26)$ \\
Socio-cultural environment & $43.3(13)$ & $56.7(17)$ & $86.7(26)$ & $13.3(4)$ & $65.0(39)$ & $35.0(21)$ \\
\hline
\end{tabular}

Table 2 summarizes the compliance of rural and urban school with the "whole school environmental mapping". It shows the average percentage consisting four type schools environmental factors (i.e. physical, economic, political and socio-cultural). The total rural and urban settings of the schools shows compliance towards three environments, which are; physical environments 
(83.3\%), political environment $(56.7 \%)$, and socio-cultural environment $(65.0 \%)$. However, among of the four school environments, the only economic environment has the lowest percentage of compliance (10.0\%).

\subsection{Body Mass Index (BMI) of rural and urban school children in Selangor}

Table 3 shows the Body Mass Index (BMI) of rural and urban school children. Based on the each of the BMI categories, the total percentage of ideal weight students were the highest value, which $38.1 \%$. However, the combination of obese and overweight student outnumbered the ideal weight student percentage, which $51.7 \%$. Alarmingly, this pattern also has shown in each rural and urban area. The ideal weight percentage was the highest, in which $33.8 \%$ of the rural area and $42.4 \%$ in the urban area. However, the combination of obese and overweight children are higher compared to the ideal weight percentage, in which $51.7 \%$ of the rural area and $51.8 \%$ in the urban area..

Table 3. Body Mass Index of rural and urban school children in Selangor

\begin{tabular}{llll}
\hline BMI & Rural \% (n) & Urban \%(n) & Total \%(n) \\
\hline Underweight & $14.5(87)$ & $5.8(35)$ & $10.2(122)$ \\
Ideal weight & $33.8(203)$ & $42.4(254)$ & $38.1(457)$ \\
Overweight & $25.7(154)$ & $25.0(150)$ & $25.3(304)$ \\
Obese & $26.0(156)$ & $26.8(161)$ & $26.4(317)$ \\
\hline Total & $100(600)$ & $100(600)$ & $100(1200)$ \\
\hline
\end{tabular}

Meanwhile, when comparing the value of obese children between urban and rural, obese students in urban schools were $0.8 \%$ greater than the rural. For overweight students, rural children have a slightly higher percentage than the urban setting of $25.7 \%$ and $25.0 \%$ respectively. However, underweight children were higher in rural schools (14.5\%) compared to $5.8 \%$ in urban schools.

\subsection{BMI status and whole-school environmental mapping}

Table 4. Whole school environmental compliance and Body Mass Index (BMI) of rural and urban school children in Selangor

\begin{tabular}{|c|c|c|c|c|c|c|c|c|}
\hline \multicolumn{9}{|c|}{ Body Mass Index (BMI) } \\
\hline & \multicolumn{2}{|c|}{ Underweight } & \multicolumn{2}{|c|}{ Ideal weight } & \multicolumn{2}{|l|}{ Overweight } & \multicolumn{2}{|l|}{ Obese } \\
\hline & $\begin{array}{l}\text { Rural } \\
(n=87)\end{array}$ & $\begin{array}{l}\text { Urban } \\
(\mathrm{n}=35)\end{array}$ & $\begin{array}{l}\text { Rural } \\
(\mathrm{n}=203)\end{array}$ & $\begin{array}{l}\text { Urban } \\
(n=254)\end{array}$ & $\begin{array}{l}\text { Rural } \\
(n=154)\end{array}$ & $\begin{array}{l}\text { Urban } \\
(n=150)\end{array}$ & $\begin{array}{l}\text { Rural } \\
(n=156)\end{array}$ & Urban $(n=161)$ \\
\hline & $\%(n)$ & $\%(n)$ & $\%(n)$ & $\%(n)$ & $\%(n)$ & $\%(n)$ & $\%(n)$ & $\%(n)$ \\
\hline \multicolumn{9}{|c|}{ Physical environment } \\
\hline Comply & $5.3(64)$ & $2.8(34)$ & $12.5(150)$ & $20.3(243)$ & $8.3(100)$ & $12.3(148)$ & $8.7(104)$ & $13.0(156)$ \\
\hline Non comply & $1.9(23)$ & $0.1(1)$ & $4.4(53)$ & $0.92(11)$ & $4.50(54)$ & $0.17(2)$ & $4.33(52)$ & $0.4(5)$ \\
\hline \multicolumn{9}{|c|}{ Economic environment } \\
\hline Comply & $0(0)$ & $0.6(4)$ & $0(0)$ & $8.5(51)$ & $0(0)$ & $5.2(31)$ & $0(0)$ & $5.7(34)$ \\
\hline Non comply & $7.3(87)$ & $2.8(31)$ & $16.9(203)$ & $16.9(203)$ & $12.8(154)$ & $9.9(119)$ & $13.0(156)$ & $10.6(127)$ \\
\hline \multicolumn{9}{|c|}{ Political environment } \\
\hline Comply & $4.8(58)$ & $1.7(20)$ & $23.1(139)$ & $11.6(105)$ & $7.8(94)$ & $6.3(76)$ & $9.2(110)$ & $6.6(79)$ \\
\hline Non comply & $2.4(29)$ & $1.3(15)$ & $5.3(64)$ & $12.4(149)$ & $5.0(60)$ & $6.2(74)$ & $3.8(46)$ & $6.8(82)$ \\
\hline
\end{tabular}

Socio-cultural environment 


\begin{tabular}{lllllllll} 
Comply & $2.9(35)$ & $2.7(32)$ & $8.3(99)$ & $17.9(215)$ & $4.3(52)$ & $11.0(132)$ & $6.1(73)$ & $11.8(141)$ \\
Non comply & $4.3(52)$ & $0.3(3)$ & $8.7(104)$ & $3.3(39)$ & $8.5(102)$ & $1.5(18)$ & $6.9(83)$ & $1.7(20)$ \\
\hline
\end{tabular}

Table 4 shows the percentage of students according to the category of BMI status based on the compliance of the school for each environmental mapping. The study identified that the percentage of school children with ideal BMI level was higher among the school that comply with "whole school environmental mapping".

Meanwhile, the percentage of overweight and obese students in the school that comply to all the environments are low if being compared with ideal weight percentage, in both rural and urban areas. However, the combination of overweight and obese percentage, it happened that, in urban, schools that comply to all of the four environments, the percentage of overweight and obese children are outnumbered the normal and underweight children. In the urban area, the schools that comply with the physical environment has a total of $25.3 \%$ of obese and overweight children, while $20.3 \%$ of them are in ideal weight. The schools that comply to the economic environment recorded $10.9 \%$ of obese and overweight children for both settings, outnumbered $8.5 \%$ of the children who are in an ideal weight.

For the rural schools, the percentage of overweight and obese children are higher for the school that does not comply with the economic environment $(25.8 \%)$ followed by socio-cultural environment $(15.4 \%)$ as the second highest. This alarming percentage shows that the obesogenic environment has become a serious problem in both rural and urban areas. In the rural schools, also shows that obese and overweight school children also higher in school that comply to "whole school environmental mapping framework" recorded $44.4 \%$. This increment happened might due to other confounding factors that need further investigation such as parents, community and physical factors outside the schools environments. However, rural school that comply to the political environment have a greater number of students at the ideal weight (139) than those that don't comply (64).

Overall, it shows that overweight and obese problem are high although the schools comply to the "whole school environmental mapping". This situation also highlights that childhood overweight and obesity apparently has become a problem in both rural and urban schools.

\section{Discussion}

\subsection{Body Mass Index (BMI) of rural and urban school children in Selangor}

Based on the findings showed the highest percentage of BMI was ideal weight, in which $38.1 \%$ of both rural and urban. Meanwhile, the lowest value was underweight, $10.2 \%$. Besides, the percentage of overweight and obese students was $51.7 \%$. It showed that total of overweight and obesity of children higher compared to underweight and ideal categories. As we compare between rural and urban schools, it showed the urban area has slightly different prevalence of children that overweight and obese as compared to the rural schools. The findings of our study similar to some previous research by Moy, Gan and Zaleha (2004) reported that a prevalence of overweight is higher in urban school children. In other words, the prevalence of childhood obesity was reported to be higher in urban compared to rural (Zalilah et al., 2006; Bong \& Safurah, 1996; Ghazali et al., 2006). Hence, the pattern of this study is almost similar, where the prevalence of overweight and obesity is higher in the urban schools compared to the rural schools.

School children usually tend to attract to high fat-food as they can afford to buy the food due to low in prices and delicious taste. Availability and affordability to consume these foods did not equal to their physical activity (Borodulin et al. (2012). Thus, the socioeconomic factors could contribute to the increases in BMI. This finding showed that most of the children from rural and urban schools were overweight and obese. Besides that, Hewitt and Stephens (2007) which identified the child's ability to select a healthy diet will primarily influence their actual body weight. In other words, if the school children were empowered to choose and have access to a healthy diet, the risk of overweight ought to be lower than those who feel unskilled in choosing healthy foods and drinks.

\subsection{BMI status and "Whole School Environmental Mapping"}

\subsubsection{Body Mass Index (BMI) and physical environment}


In the context of the physical environment at school, it may relate to the lack of facilities that may lead to the physical inactivity and less exercise. Besides, the availability of non-nutritious food also influences unhealthy eating habit among the students. Obesity or excess body weight may the result of unbalance energy intake and energy output. This relationship happens as the input exceeds the energy output (Caballero, 2007). As students spend most of their time at school, the types of food available at the school canteen may encourage students to adopt the unhealthy eating behavior. Although the school is aware that providing healthy food at canteen may improve students' health, this practice cannot be done due to some of the problems. For instance, lack of equipment, limited availability of coaches, playing spaces (Hayati, Holdsworth, McCullough \& Norimah, 2015), profit advantage and less support from management in providing healthy food (Carter \& Swinburn, 2004). Besides, the food environment in some schools was not conducive to promoting healthy food as the majority of the school canteens prefer to sell unhealthy foods (Lyn et al., 2011).

Despite unhealthy eating habits, become physically unfit also resulting in overweight and obese (Story et al., 2009). Although most of the schools made compulsory for the school children to involve sports, several teachers complained that some of the pupils, especially the overweight reluctant to take part. One of the reasons was, they felt embarrassed and had no opportunity to involve the game as it was monopolised by other students who are more active compared to them. As a result, these children more likely stand on side-lines and watching their friends doing physical activity and sports (Mahar et al., 2006).

\subsubsection{Body Mass Index (BMI) and economic environment}

Exploring the economic environment at school is also important to identify how this factor can influence student's food choice and promote physical activity, and its relationship with their BMI status. Based on our finding, food prices at the school's canteen may become one of the barriers for students to take either healthy or unhealthy food. Several teachers reported that some students are reluctant to buy healthy food as they said that healthy food (e.g. yogurt, fresh milk and cut fruits) were expensive as compared to unhealthy food. Therefore, to prevent overweight and obesity, the schools were suggested to reduce the prices of the healthy foods and monitor the food price at the school canteen. This suggestion is consistent with the finding of a previous study by Lakdawalla and Philipson (2002). The problem of overweight and obese might be related to the availability of unhealthy food at school area. The previous study also reported that some schools sell a poor choice of food and unpalatable healthy dishes (Hayati et al., 2015). The availability of competitive food and mobile caterer were strongly attributed to the factors that may explain why students have higher risk to get obese (Story et al., 2009). However, teachers do not have any authority to stop them from selling the goods. A cooperation and implementation from city council to monitor the type of foods that been sold by the existence of a mobile caterer may help in controlling the amount of unhealthy and high-calorie food to the school children.

Besides that, lack of budget to buy sports equipment also happened in rural and urban schools. This situation may hinder students from being physically active at school. Financial support was essential to school in promoting physical activity. Besides, there were also insufficient facilities to support healthy environments (e.g. a particular leisure room for health education hall, sports centre and gymnasium), and it should be given priority concern for improvement.

\subsubsection{Body Mass Index (BMI) and political environment}

Regarding the political environmental mapping, the study found that there was the availability of nutrition and physical activity guidelines or policies in the schools, as well as the existence of policies for staff to attend training programmes. The study identified that the schools have had provided standard nutritional guidelines (e.g. food pyramid, nutrient content, food label). However, some of the school canteen handlers were still not following the menu guidelines effectively. The former study also shows some of the food handlers were still not following the gazetted guidelines (Hayati et al., 2015). The school authorities should take a stern action toward the food handler that does not comply with the school's guidelines and recommendation. The policies that curb access to high-fat food and sugary beverages on the school canteen could be a promising strategy for helping children cut back non-healthy food consumption. The impact of policies on healthy eating among children has substantially reduced the supply of sugary beverages, students cut back, overall, on sweet drinks (Cradock et al., 2011).

Besides that, the lacked of the availability of policy for physical activity may become one of the factors that contribute to higher prevalence of overweight/obese in the urban school and rural school. Nearly all children spent most of their days in classes and had scheduled to do physical activity. However, the additional prerequisites are needed to boost the physical activity level among students. Increasing exercise sessions and developing physical activity skills during the school week were among 
the promising intervention for obesity (Waters et al., 2011). Any programmes that emphasise on both nutrition and physical activity seem to be more efficient at reducing children's BMI than those that focus on physical activity alone (Katz et al., 2008).

\subsubsection{Body Mass Index (BMI) and socio- cultural environment}

Culture and preference on higher dietary fat and calorie consumption among school children, and a lower frequency of exercise may lead to higher BMI among students. Based on the observation, food sold and served in the school canteen, especially junk food and sugary food, become food preference and choice among school children. Canteen handlers may need more modules to train them in understanding the culture of food choices and nutritional awareness amongst children that should be implemented while serving the food. They may need more skills in preparing food in a healthy way and providing nutritious food such as fruits, vegetables and milk (Hayati et al., 2015). Besides that, higher BMI among school children may due to the food belief, culture and preference of students. The students food beliefs, culture and preferences were influenced by another socio-cultural environment outside of school such as parental influence toward high-calorie food at home (Scaglioni, Arrizza, Vecchi, \& Tedeschi, 2011). During mealtime, the interaction between parents and young children also signify as essential educational activity (Bova \& Arcidiano, 2013). Besides, family socioeconomic status has a great impact on the physical activity level of children (Hashemi, Hojjati, Nikravan \& Feizabedi, 2013).

Regarding the preference for dense-energy food and sugary drink, it showed that rural and urban school children have a similarity in higher fat intake (Crooks, 2000). The popularity of fast foods and soft drinks, less exercise, increased television viewing, and computer use are the common trends that influenced nutrition and lifestyle of the children today (Unnithan \& Syamakumari, 2008).

Besides, based on the findings showed that unhealthy socio-cultural environment at school such as the use of unhealthy food rewards also may become one of the factors that associate with abnormal BMl among students. The use of small nutrient-dense food as a food reward/incentive may lead children become a picky eater and provide with little energy and lots of empty calories (Hayati et al., 2015). The increasing phenomenon of abnormal weight in children entitles for immediate action in both rural and urban areas. Adequate and appropriate nutritional intervention programmes that involve students and collaboration with parents and school authorities are needed (Hayati et al., 2015). The previous study shows that effective educational counseling can significantly increase the physical activity level of pupils (Dumciene \& Rakauskiene, 2013). A study was done in Slovakia also suggest that interventions should be focused particularly on children between 11 and 13 years (Baskova, Baska \& Banovcinova, 2014).

Overall, this study indicates that more health promotion's programmes and strategies have to be done to overcome the problem of childhood obesity. Further study needs to be done to assess the level of physical activity and healthy food intake among these schools children. It was known that childhood obesity did not only contributed by the school environment but it cannot be denied that hours spent by the children at school can be fully manipulated by giving and encouraging school children in practicing healthy eating and physically active.

\section{Conclusion}

The result of the study found that an alarmingly high prevalence of overweight and obesity among rural and urban school children in Selangor. Even though in some instance the schools comply with the "whole school environmental mapping", the prevalence of overweight and obese apparently high. It could be suggested that the behavioural factors such as healthy eating and physical activity have its correlation with the physical development of the surroundings. In the long run, the problem of childhood obesity may contribute to the leading chronic disease at the early ages of the children. Hence, early intervention and holistic approaches are crucial to prevent the prevalence of obesity among school children through environment-behavioural philosophy.

\section{Acknowledgements}

We would like to express our thanks to Ministry of Higher Education Malaysia for the funding given to start and accomplished this project. Our thanks also go to Research Management Institute, Universiti Teknologi MARA, teachers and staffs of the selected schools for their support. 


\section{References}

Baskova, M., Baska, T., \& Banovcinova, L. (2014). Selected aspects of dietary habits in school-aged youth in the Slovak Republic. Procedia social and behavioral sciences, 132 (2014) 129-134

Bong, A.S.L., \& Safurah, J. (1996).Obesity among years 1 and 6 primary school children in Selangor Darul Ehsan. Malaysian Journal nutrition 2, $21-7$.

Borodulin, K., Zimmer, C., Sippola, R., Mäkinen, T.E., Laatikainen, T., \& Prättälä, R. (2012).Health behaviours as mediating pathways between socioeconomic position and body mass index. International journal of behavioral medicine, 19(1), 14-22

Bova, A., \& Arcidiacono, F. (2013). "You must eat the salad because it is nutritious". Argumentative strategies adopted by parents and children in food-related discussions at mealtimes. Appetite, 73, 81-94

Caballero, B. (2007). The Global Epidemic of Obesity: an overview. Epidemiologic reviews, 29(1), 1-5.

Carter, M., \& Swinburn, B. (2004). Measuring the "obesogenic" food environment in New Zealand primary schools. Health promotion international, 19(1), 15-20.

Cradock, A.L., McHugh, A., Mont-Ferguson, H., Grant, L., Barrett, J.L., Wang, Y.C., \& Gortmaker, S.L. (2011). Effect of school district policy change on consumption of sugar-sweetened beverages among high school students, Boston, Massachusetts, 2004-2006. Preventing chronic disease, 8(4), 74.

Crooks, D.L. (2000). Food consumption, activity, and overweight among elementary school children in an Appalachian Kentucky community. American journal of physical anthropology.112 (2), 15 9-170.

Dennison, B.A., Russo, T.J., Burdick, P.A., \& Jenkins, P.L. (2004). An intervention to reduce television viewing by preschool children. Archives of pediatrics \& adolescent medicine, 158(2):170-176.

Dumciene, A., \& Rakauskiene, V. (2013).Encouragement of Physical Activity among Students by Employing Short-Term Educational Counselling. Procedia social and behavioral sciences, 116 (2014) $1523-1527$

Ghazali, S.M., Kamaluddin, M.A., Said, I.M., Isa, M.R., Ghazali, I.M.M., \& Idris, N. (2006). Obesity among school children in Kuala Selangor: a cross-sectional study. Tropical biomedicine, 23(2), 148-154.

Hashemi, M., Hojjati, A., Nirkavan, F., \& Feizabedi, M.S. (2013) The Comparison of Socio-Economic Status of Families and Social Support of Parents for the Physical Exercises of Their Children. Procedia social and behavioral sciences, 82 (2014) 375 - 379

Hayati Adilin, M. A. M., Holdsworth, M., McCullough, F., Swift, J. A., \& Norimah, A. K. (2015). Whole School Mapping to Investigate the School Environment's Potential to Promote a Healthy Diet and Physical Activity in Malaysia. Malaysian journal of nutrition, 21(1):1-14, 2015.

Hayati Adilin, M. A. M., Ajau, D., Siti Khuzaimah, A. S., \& Mastura, K. (2015). Whole School Environmental Mapping Framework and Observation in Preventing Childhood Obesity. Procedia social and behavioral sciences, 201 (2015), 102-109.

Hewitt, A.M., \& Stephens, C. (2007). Healthy eating among 10 - 13-year-old New Zealand children: understanding choice using the Theory of Planned Behaviour and the role of parental influence. Psychology, health medicine, 12 (5), 526-535.

Ismail, M.N. (2002). The nutrition and health transition in Malaysia. Public health nutrition, 5, 191-195.

Ismail, M.N., Norimah, A.K., Poh, B.K. Ruzita, A.T., Nik Shanita, S., Nik Mazlan, M., Nur Zakiah, M.S., \& Roslee, R. (2008). Nutritional status and dietary habits of primary school children in peninsular Malaysia: comparison of the 2001/02 survey with the 2007/08 survey. In Executive Summary Report for UKMNestle Research Project. Kuala Lumpur: Department of Nutrition and Dietetics, Faculty of Allied Health Sciences, Universiti Kebangsaan Malaysia, 9-10 February.

Johnson, D.B., Bruemmer, B., Lund, A.E., Evens, C.C., \& Mar, C.M. (2009). Impact of school district sugar-sweetened beverage policies on student beverage exposure and consumption in middle schools. Journal of adolescent health, 45(3), 30-37.

Katz, D.L., O'connell, M., Njike, V.Y., Yeh, M.C., \& Nawaz, H. (2008). Strategies for the prevention and control of obesity in the school setting: systematic review. International journal of obesity, 32, 1780-1789.

Kee Jr, C.C., Jamaiyah, H., Noor, S.M., Khor, G.L., Suzana, S., Jamalludin, A.R., Rahmah, R., Ahmad, A.Z., Ruzita, A.T., Wong, N.F., \& Ahmad, F. Y. (2008). Abdominal obesity in Malaysian adults: Health and Morbidity Survey III (NHMS III, 2006). Malaysian journal of nutrition,14(2), 125.

Khambalia, A.Z., Lim, S.S., Gill, T., \& Bulgiba, A.M. (2012). Prevalence and sociodemographic factors of malnutrition among children in Malaysia. Food \& nutrition bulletin, 33(1), 31-42

Kubik, M. Y., Lytle, L. A, \& Story, M. (2005). Schoolwide food practices are associated with body mass index in middle school students. Archives of pediatrics \& adolescent medicine, 159(12), 1111-4

Lakdawalla, D., \& Philipson, T. (2002). The growth of obesity and technological change: a theoretical and empirical examination (No. w8946). National Bureau of Economic Research.

Lobstein, T., \& Jackson-Leach, R. (2007). Child overweight and obesity in the USA: prevalence rates according to IOTF definitions. International journal of pediatric obesity, 2(1), 62-64.

Lyn, R., Maalouf, J., Davis, T., Connell, S., \& Smith, M. (2011).Philanthropic Collaborative for a Healthy Georgia. Healthy Schools, Healthy Communities: A Guide for Preventing Childhood Obesity in Georgia. Atlanta, Georgia Health and Policy Centre. Retrieved from http://ghpc.gsu.edu/download/healthyschools-healthy-communities-a-guide-for-preventing-childhood-obesity-in-georgia-15/

Mahar, M. T., Murphy, S. K., Rowe, D. A, Golden, J., Shields, A. T., \& Raedeke, T.D. (2006).Effects of a classroom-based program on physical activity and ontask behavior.Medicine and Science in Sports and Exercise 38(12): 2086-94.Medicine,158(2), 170.

Moy, F.M., Gan, C.Y., \& Zaleha, M.K.S. (2004). Body mass status of school children and adolescents in Kuala Lumpur, Malaysia. Asia Pacific journal of clinical nutrition, 13(4), 324-329.

National Centers for Disease Control and Prevention (NCDC). (2011). Health, United States, 2011: with special features on socioeconomic status and health. Hyattsville, MD: U.S. Department of Health and Human Services.

Ogden, C.L., Carroll, M.D., Kit, B.K., \& Flegal, K.M. (2012). Prevalence of obesity and trends in body mass index among US children and adolescents, 19992010. The journal of the American Medical Association, 307(5), 483-490.

Powell, L.M. (2009). Fast food costs and adolescent body mass index: evidence from panel data. Journal of health economics, 28(5), 963-970. 
Scaglioni, S., Arrizza, C., Vecchi, F., \& Tedeschi, S. (2011). Determinants of children's eating behavior. The American journal of clinical nutrition, 94(6): 20062011.

Story, M., Nanney, M.S., \& Schwartz, M.B. (2009). Schools and obesity prevention: creating school environments and policies to promote healthy eating and physical activity. Milbank quarterly, 87(1), 71-100.

Trost, S.G., Sallis, J.F., Pate, R.R., Freedson, P.S., Taylor, W.C., \& Dowda, M. (2003). Evaluating a model of parental influence on youth physical activity. American journal of preventive medicine, 25(4), 277-282.

Unnithan, A.G., \& Syamakumari, S. (2008). Prevalence of overweight, obesity and underweight among school going children in rural and urban areas of 115 Thiruvananthapuram Educational District, Kerala State (India). The internet journal of nutrition and wellness, 6(2), 10-15.

Wang, L., Kong, L., Wu, F., Bai, Y., \& Burton, R. (2005). Preventing chronic diseases in China. The lancet, 366 (9499): 1821-1824.

Waters, E., de Silva-Sanigorski, A., Hall, B.J., Brown, T., Campbell, K. J., Gao, Y., Armstrong, R., Prosser, L., \& Summerbell, C.D. (2011). Interventions for preventing obesity in children. Cochrane database systematic reviews, 12, 1-223.

World Health Organization. (2003). Obesity and Overweight. Global Strategy on Diet, Physical Activity and Health. Retrieved from http://www.who.int/dietphysicalactivity/media/en/gsfs_obesity.pdf

World Health Organization.(2011).Non-Communicable Disease Country Profiles. Retrieved from http://www.who.int/nmh/countries/en/

Zalilah, M.S., Mirnalini, K., Khor, G.L., Merlin, A., Bahaman, A.S., \& Norimah, K. (2006). Estimates and distribution of body mass index in a sample of Malaysian adolescents. Medical journal of Malaysia, 61(1), 48-58. 